\title{
Upaya Peningkatan Prestasi Belajar Pendidikan Kewarganegaraan (PKn) Melalui Metode Pembelajaran Make a Match pada Siswa Kelas III B di SD Islam NDM Kauman Surakarta
}

\author{
Sri Maryati ${ }^{1}$ \\ * Corresponding Author. E-mail: ${ }^{1}$ Hasrimaryati129@gmail.com
}

Receive: $13 / 05 / 2021$

Accepted: 23/08/2021

Published: 01/10/2021

Penelitian ini bertujuan untuk mengetahui peningkatan prestasi hasil belajar peserta didik melalui metode make a match pada mata pelajaran pendidikan kewarganegaraan ( $\mathrm{PKn}$ ). Penelitian ini termasuk penelitian PTK. Populasi dalam penelitian ini adalah seluruh peserta didik kelas III B SD Islam NDM Kauman Surakarta. Sampel dalam penelitian ini adalah peserta didik kelas III B. Data diperoleh dari hasil obervasi,wawancara dan dokumentasi. Analisis data dengan cara deskritif komparatif dan kritis. Hasil penelitian menunjukkan bahwa hasil belajar PKn peserta didik masuk kategori relatif rendah dibuktikan 11 peserta didik yang belum tuntas mencapai KKM. Setelah adanya tindakan siklus 1 dan 2 dengan metode make a match, terlihat hasil belajar siswa pada mata pelajaran PKn meningkat. Pada siklus 1 yang tuntas KKM ada 18 anak dan pada siklus 2 terlihat hasil semua siswa tuntas dari KKM yang ditentukan.

Kata Kunci : Prestasi Belajar, Metode Make A Match

\begin{abstract}
This research aims to find out the improvement in the achievement of students' learning outcomes through make a match method in citizenship education subjects (PKn). This research includes PTK research. The population in this study was all students grade III B SD Islam NDM Kauman Surakarta. The samples in this study were class III B students. Data was obtained from obervasi results, interviews and documentation. Analyze data in a comparative and critical manner. The results showed that the results of the study of students in the relatively low category were evidenced by 11 students who had not completed reaching KKM. After the action of cycles 1 and 2 with the make a match method, students' learning outcomes in the primary school subjects increased. In cycle 1 that completes KKM there are 18 children and in cycle 2 is seen the results of all completed students from the specified KKM.
\end{abstract}

Keywords : Learning Achievements, Make A Match Method 


\section{Pendahuluan}

Abad 21, memiliki dampak yang luar biasa dalam berbagai sendi kehidupan manusia. Tak terkecuali dalam dunia pendidikan. Ada beragam tantangan dalam dunia pendidikan di antaranya dalam hal karakter anak bangsa.

Perkembangan teknologi informasi yang pesat di abad 21, membawa dampak besar bagi anak bangsa. Perkembangan teknologi informasi semacam sebuah paradoks, satu sisi memberi kemudahan dalam memperoleh informasi di sisi lain juga memunculkan beragam dampak negatif. Dampak negatif diantaranya terlihat dari dekadensi moral generasi muda, seperti adanya tawuran antar pelajar, pornografi, pergaulan seks bebas dan lainnya.

Dekadensi moral tersebut perlu segera di atas, agar tidak menimbulkan bahaya yang lebih parah dan mengahancurkan bangsa Indonesia. Untuk mengatasi dekadensi moral tersebut di antaranya melalui dunia pendidikan.

Pendidikan menjadi kunci untuk memajukan bangsa Indonesia. Kemajuan itu dibentuk dari hal penguatan dan pengembangan karakter anak bangsa. Salah satu pelajaran yang memberi peran penting dalam penguatan karakter yaitu pendidikan kewarganegaraan.

Pendidikankewarganegaraan

merupakan salah satu mata pelajaran yang ada dalam kurikulum sekolah. Dalam mata pelajaran ini bertujuan guna mengembangkan moral serta kualitas mutu kehidupan dan martabat manusia Indonesia yang berkepribadian Indonesia sesuai dengan tujuan pendidikan nasional(Syam, 2011:109).

Dalam hal ini Pendidikan kewarganegaraan sangat penting sebagai mata pelajaran yang diberikan kepada siswa sebagai wujud pemebentukan karakter yang kuat dan baik, guna memajukan bangsa Indonesia. Hal ini dapat dilihat dalam setiap jenjang sekolah dari SD hingga perguruan tinggi pasti ada mata pelajaran tersebut.

Akan tetapi dalam proses pembelajarannya sering kali guru, kurang kreatif dan inovatif. Sehingga membuat siswa bosan, kurang tertarik ataupun mudah melupakan materi dalam mata pelajaran tersebut. Kejadian semacam di atas mempengaruhi keberhasilan belajar.

Hal ini sebagaimana yang dituliskan dalam penelitian Darma,dkk(2020:352) dinyatakan bahwa keberhasilan proses belajar peserta didik ditentukan oleh guru sebagai pendidik. Pendidikan harus kreaktif dalam mengajar peserta didik.

Hal ini semacam yang terjadi dalam proses pembelajaran di SD Islam NDM khususnya kelas III B tentang "Makna Sumpah Pemuda" pada mata pelajaran pendidikan kewarganegaraan. Terlihat prestasi siswa hasil belajar siswa masih sangat rendah dan terlihat siswa kurang antusias. Sehubungan dengan prestasi belajar, Purwanto (2003:28) memberikan pengertian prestasi belajar yaitu "hasil yang dicapai oleh seseorang dalam usaha belajar sebagaimana yang dinyatakan dalam raport". Dalam pendapat lainnya dijelaskan 
bahwa prestasi belajar dan output pendidikan yang bermutu tinggi adalah hasil dari proses belajar mengajar yang berkualitas (Kotten,2005:2)

Berdasarkan hal di atas, peneliti mencoba melakukan inovasi dalam metode pembelajaran. Metode mengajar adalah suatu cara/jalan yang perlu dilakukan di dalam proses mengajar siswa (Sulastri, Imran, dan Firmansyah 2015:93). Pada proses pelajaran mapel PKn yang sebelumnya biasanya sekedar ceramah, dan diskusi/tanya jawab yang cenderung pasif. Kini ada modifikasi dengan menggunakan metode Make A Match pada mapel pendidikan kewarganegaraan (PKn) di kelas III B SD Islam NDM Kauman Surakarta Semester I pada Tahun Pelajaran 2015/2016. Dengan tujuan agar dapat meningkatkan prestasi belajar siswa. Adanya peningkatan prestasi, diharapkan dapat meningkatkan pemahaman belajar dan penguatan karakter siswa.

\section{Metode}

\section{Pendekatan dan Metode Penelitian}

Penelitian ini merupakan penelitian tindakan kelas (PTK). Menurut Kunandar (2008: 46) PTK mengandung pengertian bahwa PTK adalah sebuah bentuk kegiatan refleksi diri yang dilakukan oleh para pelaku pendidikan dalam suatu situasi kependidikan untuk memperbaiki rasionalitas dan keadilan tentang: (a) Praktikpraktik kependidikan mereka, (b) Pemahaman mereka tentang praktik-praktik tersebut, dan (c) situasi dimana praktik-praktik tersebut dilaksanakan. Penelitian ini berfokus pada mata pelajaran Pendidikan Kewarganegaan (PKn) untuk peningkatan prestasi peserta didik pada bab makna sumpah pemuda melalui metode make a match .

\section{Latar Penelitian}

Penelitian ini dilakukan di kelas III B SD Islam NDM Kauman. Terletak di jalan Trisula 4/ VI Kauman Pasarkliwon, Surakarta. Untuk subjek penelitian adalah seluruh peserta didik kelas III B SD Islam NDM Kauman yang berjumlah 21 .

\section{Sumber Data dan Teknik Pengumpulan Data}

Sumber data dalam penelitian ini setidaknya terbagi menjadi 2 yaitu:

1. Data Primer

Data primer adalah data yang langsung didapatkan dari lapangan melalui proses observasi dalam penelitian langsung ini data primer didapatkan dari seluruh peserta didik kelas III B SD Islam NDM Kauman yang berjumlah 21 melalui observasi dan wawancara pertanyaan kepada siswa.

2. Data Sekunder

Data sekunder adalah data yang diperoleh secara tidak langsung data sekunder diperoleh dari dokumentasi data siswa-siswa di kelas III.

\section{Alat Pengumpulan Data}

Alat pengumpulan data adalah teknik dalam mengumpulkan data yang akan dituliskan dalam laporan penelitian berupa:

a. Metode Observasi

Observasi adalah suatu teknik yang dilakukan dengan cara mengadakan pengamatan secara teliti dan sistematis 
.Pengumpulan data melalui observasi dilakukan sendiri oleh peneliti pada kelas yang dijadikan sempel untuk mendapatkan gambaran secara langsung kegiatan siswa di kelas.

b. Metode Wawancara dan Tes

Metode wawancara dilakukan dengan memberikan beberapa pertanyaan kepada siswa maupun latihan atau alat lain untuk mengukur keeterampilan, pengetahuan, intelegensi, kemampuan atau bakat yang dimiliki oleh individu atau kelompok.

Bentuk tes berupa uraian, karena dengan tes uraian akan terlihat kemampuan siswa dalam mempresentasikan setiap soal yang diberikan disamping melihat langkah-langkah pengerjaan dari soal.

c. Metode Dokumentasi

Dokumentasi merupakan metode untuk memperoleh atau mengetahui sesuatu dengan buku-buku, arsip, yang berhubungan dengan yang diteliti.Dokumentasi digunakan untuk memperoleh data siswa,serta foto proses tindakan penelitian.

Untuk selanjutnya dalam teknik analisis data pada penelitian tindakan kelas ini, melalui cara analisis data mulai dari tindakan pembelajaran dilakukan hingga adanya pengembangan dari refleksi sampai proses penyusunan laporan. Untuk kesinambugan dan kedalaman pada pengajaran, data penelitian ini dianalisis secara deskritif komparatif dan kritis.

Teknik analisis yang digunakan yaitu analisis deskriptif komparatif dan kritis, melalui cara menjabarkan dan menganalisis prestasi belajar PKn siswa, tentang pokok bahasan makna sumpah pemuda dari kondisi awal, siklus I dan siklus 2

\section{Hasil dan Pembahasan}

Dalam observasi melalui data dokumen diperoleh informasi bahwa pada pembelajaran sebelumnya ada 11 siswa yang belum tuntas KKM dan 10 siswa tuntas KKM. Hal di atas menjadi acuan pra siklus.

\section{a. Tahap Siklus 1.}

Siklus 1 dilakukan dengan adanya perencanaan penggunaan metode make a match, tindakan berupa pelaksaaan pembelajaran dengan metode make a match, pengamatan/ observasi pada proses belajar dengan make a match, evaluasi dan refleksi.

Tabel 1 data hasil evaluasi siklus I dengan metode make a match.

\begin{tabular}{|c|c|}
\hline Interval & Frekuensi \\
\hline $60-64$ & 3 \\
\hline $65-69$ & 4 \\
\hline $70-74$ & 7 \\
\hline $75-79$ & 4 \\
\hline $80-84$ & 4 \\
\hline $85-89$ & - \\
\hline
\end{tabular}




\begin{tabular}{|l|l|}
\hline $90-94$ & 1 \\
\hline $95-99$ & - \\
\hline
\end{tabular}

Perhitungan hasil belajar sebagai berikut (Purwanto, 2009:102):

\section{$N A=\quad$ Jumlah skor yang diperoleh $\mathrm{x} 100 \%$ Jumlah skor maksimal}

Keterangan:

$\mathrm{NA}=$ Nilai Akhir

Siswa dikatakan tuntas apabila NA $\geq 65$

Berdasarkan hasil evaluasi pembelajaran dengan KKM 65, pada siklus I menunjukkan bahwa dari 21 siswa Kelas III B SD Islam NDM Kauman Surakarta Tahun Pelajaran 2015/2016, yaitu siswa yang tuntas sebanyak 18 siswa $(85,72 \%)$ dan siswa yang tidak tuntas sebanyak 3 siswa $(14,28 \%)$.

\section{b. Tahap Siklus 2}

Pada tahap ini dilakukan perbaikan atas hasil evaluasi dan refleksi dari siklus 1 untuk peningkatan hasil belajar.

Tabel 2, Hasil evaluasi siklus II dengan metode make a match.

\begin{tabular}{|l|l|}
\hline \multicolumn{1}{|c|}{ Interval } & \multicolumn{1}{c|}{ Frekuensi } \\
\hline $65-69$ & 2 \\
\hline $70-74$ & 3 \\
\hline $75-79$ & 5 \\
\hline $80-84$ & 9 \\
\hline $85-89$ & 2 \\
\hline
\end{tabular}

Berdasarkan hasil evaluasi pembelajaran siklus II menunjukkan bahwa dari 21 siswa Kelas III B SD Islam NDM Kauman Surakarta Tahun Pelajaran 2015/2016, diperoleh semua siswa dinyatakan tuntas $(100 \%)$ dari $\mathrm{KKM} \geq 65$.

Tabel 3

Ketuntasan Prestasi Hasil Belajar PKn Pokok Bahasan Makna Sumpah Pemuda Dari Pra Siklus, Siklus I dan Siklus II Pada Siswa Kelas III B SD Islam NDM Kauman Surakarta Tahun Pelajaran $2015 / 2016$

\begin{tabular}{|l|c|c|c|c|}
\hline No & Kentutntasan & $\begin{array}{c}\text { Pra } \\
\text { Siklus }\end{array}$ & $\begin{array}{c}\text { Siklus } \\
1\end{array}$ & $\begin{array}{c}\text { Siklus } \\
2\end{array}$ \\
\hline 1 & Tuntas & 10 & 18 & 21 \\
\hline 2 & $\begin{array}{c}\text { Belum } \\
\text { Tuntas }\end{array}$ & 11 & 3 & - \\
\hline
\end{tabular}

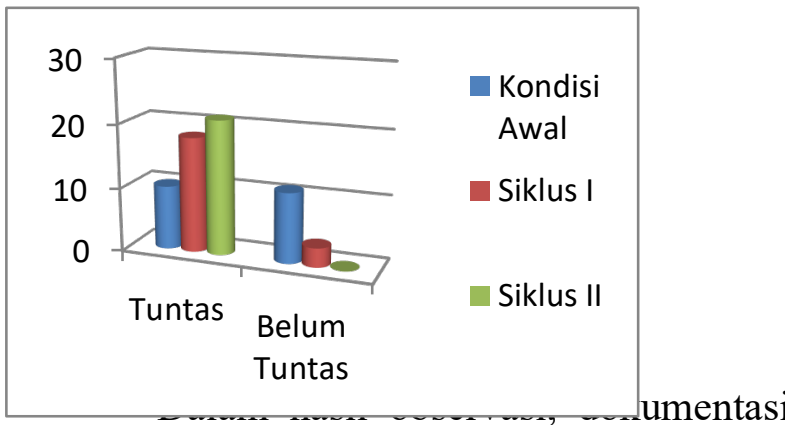

dan wawancara dengan guru kelas diperoleh informasi terlihat aktivitas siswa dalam proses pembelajaran yang cenderung pasif, ketika guru menanyakan kepada siswa, siswa saling menunjuk temannya untuk menjawab pertanyaan yang diberikan guru. Ketika seorang siswa menjawab pertanyaan dari guru tidak ada satu pun siswa yang menanggapi hasil jawaban dari temannya.

Pada pelaksanaan pembelajaran, siswa terlihat kurang antusias terhadap pelajaran, mereka terlihat kurang dapat mengikuti kegiatan belajar mengajar dengan 
baik. Hal itu diketahui dari kurangnya rasa ingin tahu mereka terhadap materi yang akan diberikan. Kebanyakan dari mereka kelihatannya jenuh terhadap pelajaran. Karena motivasi siswa terhadap pelajaran kurang, maka prestasi belajar mereka juga kurang maksimal. Hal ini juga terlihat dari hasil prestasi belajar siswa ketika pra siklus di mana hanya 10 orang yang tuntas KKM.

Pada siklus 1 dengan adanya penerapan metode make a match, terlihat siswa mulai aktif dan antusias belajarnya. Walaupun ada beberapa yang masih pasif dan bercakap sendiri. Hal yang perlu diperbaiki dari hasil siklus 1, akan dibuatkan catatan untuk dijadikan rencana perbaikan dalam siklus 2. Dalam siklus 1 terlihat ada peningkatan siswa yang tuntas KKM meningkat menjadi 18 siswa dari sebelumnya hanya 10 siswa.

Selanjutnya pada siklus 2, pelaksanaan tindakan pada siklus II, secara keseluruhan sudah terlaksana dengan baik. Siswa mulai terbiasa dengan model pembelajran mencari pasangan yang diterapkan guru. Siswa tampak bersemangat mengikuti pembelajaran. Siswa berdiskusi dengan baik, mereka bekerja sama, saling membantu dan saling menghargai pendapat dalam menyelesaikan tugas yang diberikan guru.
Pada siklus II guru dapat mengkondisikan belajar siswa dengan baik, siswa mampu memusatkan perhatian pada materi pembelajaran yang disampaikan oleh guru, saat pembelajaran berlangsung semua siswa tampak aktif, pada tahap pelaporan hasil diskusi sudah terlaksana dengan baik. Hal ini terlihat semua siswa merasa percaya diri saat mengajukan dan menanggapi pertanyaan. Pembelajaran berlangsung menyenangkan, hal ini terlihat dari sikap siswa yang tampak gembira saat menyelesaikan tugas yang diberikan guru. Tugas yang diberikan kepada mereka tidak lagi menjadi beban berat yang harus mereka kerjakan tetapi menjadi tugas yang menyenangkan.

Kondisi di atas mempengaruhi keberhasilan belajar dan prestasi belajar siswa. Hal ini terlihat dari adanya peningkatan hasil belajar siswa, di mana 21 siswa mampu tuntas hasil belajarnya dengan memperoleh nilai di atas $K K M \geq 65$.

\section{Simpulan}

Berdasarkan hasil penelitian tentang pengaruh penggunaan metode metode make a match, terhadap prestasi hasil belajar siswa kelas III B SD Islam NDM Kauman Surakarta Tahun Pelajaran 2015/2016 pada mata pelajaranPendidikan Kewarganegaraan (PKn), maka dapat ditarik kesimpulan bahwa terdapat pengaruh penggunaan metode make a match terhadap prestasi hasil belajar siswa. Hal ini berdasarkan dari hasil evaluasi mulai dari pra siklus, siklus 1 dan siklus 2 terlihat ada 
peningkatan ketuntasan KKM, dari pra siklus yang 10 siswa tuntas, kemudian siklus 1 meningkat menjadi 18 siswa dan pada siklus 2 meningkat menjadi 21 siswa tuntas di atas KKM. Maka dapat diketahui bahwa metode make a match dapat meningkatkan motivasi belajar siswa yang semakin antusias dan pada akhirnya mampu meningkatkan prestasi hasil belajar siswa.

\section{Daftar Pustaka}

Darma, Darma, Khaeruddin Khaeruddin, and

Evi Ristiana. 2020. "PENINGKATAN KEMAMPUAN LITERASI SAINS BERBASIS MODEL PROBLEM BASED LEARNING SISWA KELAS V SD." Jurnal Edumaspul 4 (1): 350-57.

Ibrahim, H. Muslimin. 2000. Pembelajaran Kooperatif. Surabaya: University Press

Kunandar. 2009. Penelitian Tindakan Kelas Sebagai Pengembangan Profesi Guru. Jakarta: Rajawali Press.

Kotten. Natsir B. 2005, Upaya Pengembangan Profesionalisme Guru Sekolah Dasar, JURNAL ILMU PENDIDIKAN Universitas Negeri Malang, Jilid 12 No 1

$$
\begin{aligned}
& \text { Purwanto Ngalim, 2009,Psikologi } \\
& \text { Pendidikan, Bandung : Remaja } \\
& \text { RosdaKarya }
\end{aligned}
$$

Sulastri, Imran, and Arif Firmansyah. 2015. "Meningkatkan Hasil Belajar Siswa Melalui Strategi Pembelajaran Berbasis Masalah Pada Mata Pelajaran IPS Di Kelas $\vee$ SDN 2 Limbo MMakmur Kecamatan Bumi Raya." Jurnal Kreatif Tadulako Online 3 (1): 90-103.

Syam, Norman. 2011. "PENINGKATAN KUALITAS PEMBELAJARAN PKn DI

\author{
SEKOLAH DASAR MELALUI MODEL \\ PENGAJARAN BERMAIN PERAN." \\ Perspektif Ilmu Pendidikan - 24: 108- \\ 12.
}

\section{Profil Penulis}

Sri Maryati, Lahir di Surakarta, Jawa Tengah pada tanggal 12 September 1966, anak keempat dari delapan bersaudara pasangan Hadi Muntalib dan Watinem.

Bulan Pebruari tahun 1988 Penulis menikah dengan Ir.Muhammad Hasran, yg berasal dari Muara Enim, Sumatera Selatan.Penulis mulai menempuh pendidikan Sekolah Dasar ( 1973 - 1980), Sekolah Menengah Pertama ( 1980 -1983), Sekolah Pendidikan Guru ( SPG) ( 1983- 1986 ) .Tahun $1986-.1989$, penulis mengabdi di sebuah SD Swasta, SD Islam NDM, yg terletak di Kelurahan Kauman, Kecamatan Pasarkliwon, Kota Surakarta, Jawa Tengah.

Kemudian Pada tahun 1989- 1995 Mengikuti suami pergi ke Sumatera.Tahun 1995 kembali ke Solo, mengajar di SD NDM lagi. Tahun 2005, Kuliah D2 PGSD Universitas Terbuka ( UT ) sampai tahun 2007 .Pada tahun 2008 diangkat sebagai PNS. Kemudian melanjutkan Kuliah lagi pada jurusan PGSD S1 di Universitas Terbuka (UT) Surakarta pada tahun 2007 sampai 2010. 